\title{
Polymorphisms at Three Introns in the Manila Clam (Ruditapes philippinarum) and the Grooved Carpet-Shell Clam (R. Decussatus)
}

Author(s): David Cordero, Juan B. Peña, Carlos Saavedra

Source: Journal of Shellfish Research, 27(2):301-306. 2008.

Published By: National Shellfisheries Association

DOI: http://dx.doi.org/10.2983/0730-8000(2008)27[301:PATIIT]2.0.CO;2

URL: http://www.bioone.org/doi/full/10.2983/0730-8000\%282008\%2927\%5B301\%3APATIIT

$\% 5 \mathrm{D} 2.0 . \mathrm{CO} \% 3 \mathrm{~B} 2$

BioOne (www.bioone.org) is a nonprofit, online aggregation of core research in the biological, ecological, and environmental sciences. BioOne provides a sustainable online platform for over 170 journals and books published by nonprofit societies, associations, museums, institutions, and presses.

Your use of this PDF, the BioOne Web site, and all posted and associated content indicates your acceptance of BioOne's Terms of Use, available at www.bioone.org/page/terms_of_use.

Usage of BioOne content is strictly limited to personal, educational, and non-commercial use. Commercial inquiries or rights and permissions requests should be directed to the individual publisher as copyright holder. 


\title{
POLYMORPHISMS AT THREE INTRONS IN THE MANILA CLAM (RUDITAPES PHILIPPINARUM) AND THE GROOVED CARPET-SHELL CLAM (R. DECUSSATUS)
}

\author{
DAVID CORDERO, JUAN B. PEÑA AND CARLOS SAAVEDRA* \\ Instituto de Acuicultura de Torre de la Sal, Consejo Superior de Investigaciones Cientificas, Ribera de \\ Cabanes, 12595 Castellón, Spain
}

\begin{abstract}
We have designed a set of exon-primed intron-crossing (EPIC) PCR primers to amplify introns at the genes TBP and SRP54 in the Manila clam (Ruditapes philippinarum) and the grooved carpet-shell clam (R. decussatus), and also one intron at a histone 3 homologous gene in the Manila clam. The primers were developed by using "universal" EPIC primers available in the literature and by searching for intron locations in cDNA sequences taken from public databases. The identity of the amplified products was checked by sequencing. The three introns of the Manila clam, and one in the carpet shell clam (TBP), exhibited length polymorphisms. The number of alleles was two at the TBP locus of the grooved carpet-shell clam, and ranged from three to five in the three loci of the Manila clam. The locus without length polymorphism in the carpet-shell clam exhibited polymorphism when digested with the restriction enzyme $E c o$ R I (4 haplotypes). The variability of the markers was examined in two population samples in each species.
\end{abstract}

KEY WORDS: intron, EPIC-PCR, Manila clam, grooved carpet-shell clam, Ruditapes

\section{INTRODUCTION}

The Manila clam (Ruditapes philippinarum Adams \& Reeve) is a native species from the Indo-West Pacific coast. Currently, this clam is the second most important bivalve species in world aquaculture, with nearly 3 million Tm produced in year 2005 (http://www.fao.org/figis). The Manila clam was introduced in the Pacific coast of North America in the decade of 1930, and in Europe in the decade of 1980 (Flassch \& Leborgne 1992, Paesanti \& Pellizzato 2000). It showed a high adaptability to these new areas, including the ability to reproduce and give rise to self-sustaining populations (Flassch \& Leborgne 1992, Pranovi et al. 2006, Jensen et al. 2004), which now form the basis of a fishery. Aquaculture techniques have been developed in the Manila clam (Helm \& Pellizzato 1990, Jones et al. 1993), and natural recruitment in natural beds is currently enhanced with hatchery produced spat (Paesanti \& Pellizzato 2000).

Other clam species are also important in Europe from a commercial point of view, among which the grooved carpet-shell clam (Ruditapes decussatus L.), that ranges from England to Senegal in the NE Atlantic, and all along the Mediterranean coasts, is the most valuable. The spread of $R$. philippinarum has posed a problem to $R$. decussatus, because they occupy a similar habitat. Populations of $R$. decussatus have been replaced by R. philippinarum at some localities (Pranovi et al. 2006), and coexist at others (our own observations). Studies of morphological, mitochondrial DNA and 5S nuclear DNA variation have demonstrated hybridization between the two species in a Spanish locality (Hurtado et al. 2006). Hatchery production of grooved carpet-shell clams is now in a research and development phase, with the aim of replenishing wild beds that have been depleted by overharvesting and competition with $R$. philippinarum.

In spite of the aquaculture potential and management problems raised by their culture and exploitation, genetic studies on these clam species have been scarce. Until recently, population genetic studies on Ruditapes clams had been based on protein polymorphisms detected by starch gel electrophoresis, also known as "allozymes" (Borsa et al. 1994, and

\footnotetext{
*Corresponding author. E-mail: saavedra@iats.csic.es
}

references therein). Nuclear DNA markers were not available until the very recent publication of nine microsatellite primers in the Manila clam (Yasuda et al. 2007). The development of additional DNA markers is desirable in the two species dealt with here, for a number of applications, which include population genetic studies, parentage analysis in hatcheries and genetic mapping.

We report here on the development of a set of nuclear DNA markers based on introns in the Manila and the grooved carpetshell clams. Introns are the noncoding segments separating the coding fragments in which most eukaryotic genes are divided. Introns are a good source of genetic markers because they can show different types of polymorphisms, such as intron length polymorphisms (ILP) or restriction fragment length polymorphisms (RFLP). These two kinds of polymorphisms can be easily detected at low cost in agarose or polyacrylamyde gels. Additional polymorphism at the nucleotide level can be detected by indirect methods such as SSCP or DGGE (Lessa 1992), or directly by sequencing (Villablanca et al. 1998). The possibility to study the nucleotide sequence in combination with size polymorphism makes them, in many situations, more useful than other markers based in fragment-size differences, such as microsatellites.

Introns show often moderate to high levels of length polymorphisms, and levels of nucleotide variability that are usually higher than in exons, which are more constrained. In addition, the more conserved sequences of the flanking exons can be used to design PCR primers that amplify the intron (Lessa 1992, Corte-Real et al. 1994, Ohresser et al. 1997). This approach has been termed "exon-primed intron-crossing (EPIC) PCR" (Palumbi \& Baker 1994). Exon conservation facilitates intron study in a given species or even across a group of taxa (from congeneric species to different phyla, depending on the level of conservation of the exon). This approach has been used to design EPIC primers that amplify introns in several zoological groups (Hassan et al. 2002, Touriya et al. 2003, Corte-Real et al. 1994, Jarman et al. 2002).

We have used primer sets reported in the literature to develop specific EPIC markers for each clam species. We have 
also mined public DNA databases to obtain clam coding sequences and searched for intron positions by comparing these sequences with those of their putatively orthologous genes in model organisms. Finally, we have checked the level of polymorphism of the developed markers in population samples.

\section{MATERIALS AND METHODS}

\section{DNA Extraction}

Clam individuals of the two species were obtained in the local market and DNA was extracted from adductor muscle, using the DNAeasy Tissue Kit (QIAGEN). DNA was eluted with $100 \mu \mathrm{l}$ of buffer $\mathrm{AE}$ (provided with the kit) and stored at $-80^{\circ} \mathrm{C}$.

\section{Intron Marker Development}

We used two different approaches to obtain intron markers in clams. In one approach, primers that are reported to amplify introns in a wide range of species were taken from the literature, and were tested on clam DNA (Palumbi 1996, Jarman et al. 2002). We selected the primer pairs that gave PCR products consisting in clear one or two-banded phenotypes in agarose gels, with band sizes larger than the expected size if there were no intron (usually less than $250 \mathrm{bp}$ ). Primer pairs giving multibanded products, or simply no product at all, were discarded from further studies. PCR products from selected primer pairs were extracted from the gel, resuspended in TE, and reamplified with the same primers and PCR conditions. Reamplified PCR products from three individuals were then ligated into pGEM T-Easy (Promega) according to manufacturer instructions. Ligated plasmids were used to transform competent Escherischia coli DH5 $\alpha$ cells, which were plated on LB medium with ampicillin added (LB + Amp). The X-gal plus IPTG method was used to distinguish colonies that contained inserts from those that did not (Sambrook \& Russell 2001). Six colonies from each plate were picked and grown overnight in $3 \mathrm{ml}$ of LB + Amp. Plasmids were recovered with the Quiagen Plasmid Spin kit. The inserts were sequenced with primers T7 and SP6 in an ABI 3700 automated sequencer at the DNA Sequencing Service of the University of Valencia (Spain). The insert sequence ends were aligned on the homologous exon regions of the same genes in model species Drosophila melanogaster and Caenorhabditis elegans to check their identity. Then, new clam species-specific primers were designed for each intron by using the program PRIMER 3 (Rozen \& Skaletsky 2000).

In a second approach, we mined the public genetic data bases for clam coding genomic or cDNA sequences. We selected five accessions containing partial sequences of clam nuclear genes from cDNAs. We used these sequences to search for their closest orthologous genes in four model organisms (the mouse Mus musculus, the fruit fly Drosophila melanogaster, the worm Caenorhabditis elegans and the sea urchin Strongylocentrotus purpuratus) by using TBLASTX (McGinnis \& Madden 2004). The mouse, fly, and worm sequences with the highest E-val were retrieved from the GenBank database by following the links to the Entrez Gene web pages that appeared in the TBLASTX screen output. The model organisms' sequences were translated into amino acid sequences using Bioedit (Hall 1999) and then aligned with CLUSTAL W (Thompson et al. 1994), as implemented in BioEdit. Intron positions in each model species were established from the corresponding GenBank accessions. Finally, clam cDNAs were also translated into amino acid sequences and aligned to the model organisms' sequences. Clam introns were inferred to occur in those positions where an intron was conserved in at least two of the model organisms examined. Primers around these positions were designed from the clam cDNA sequence with PRIMER 3.

When an intron length polymorphism was observed, intron allele designations were done by assigning to each allele the length obtained from its sequence.

\section{Intron PCR}

PCR reactions with universal primers were carried out for 35 cycles of $30 \mathrm{sec}$ denaturation at $94^{\circ} \mathrm{C}, 30 \mathrm{sec}$ hybridization at $45^{\circ} \mathrm{C}$ and $60 \mathrm{sec}$ elongation at $72^{\circ} \mathrm{C}$, preceded of an initial denaturation step of $2 \mathrm{~min}$ at $94^{\circ} \mathrm{C}$, and followed by a final elongation step at $72^{\circ} \mathrm{C}$ for $3 \mathrm{~min}$. For species-specific primers, PCR conditions were the same, except that the elongation time was increased to $90 \mathrm{sec}$ and annealing temperature was $58^{\circ} \mathrm{C}$

\section{ILP and RFLP Scoring}

The existence of length polymorphisms in the amplified introns was checked by running PCR products in $1.5 \%$ agarose gels, with tris-borate-EDTA (TBE) buffer and ethidium bromide staining. The existence of restriction fragment length polymorphisms was checked in those introns that showed no ILP. A set of eight restriction enzymes was used, which included two six-cutter (BamH I and EcoR I) and six four-cutter (Dde I, Dra I, Hae III, Hinf I, Msp I, Rsa I). Ten microliters of PCR product were digested with $0.1 \mathrm{U}$ of enzyme in $20-\mu \mathrm{L}$ reactions, with the buffer supplied by the enzyme manufacturer. Fragments were scored in 2\% agarose/TBE gels. Gels were stained with $0.05 \%$ ethidium bromide, DNA fragments visualized on a UV screen and images captured with an Alpha-Innotech Image Analyser. Haplotypes defined by multiple enzymes were checked by sequencing.

\section{Allele Sequencing}

To obtain the sequence of the intron length variants, the intron bands of heterozygous individuals were extracted from the gel and reamplified with the original primers and PCR conditions. Reamplified PCR products were cleaned with the Ultra Clean PCR clean-up DNA purification kit (MOBIO) and sequenced at the DNA Sequencing Service of the University of Valencia using an ABI 3700 automated sequencer. For RFLP variants, PCR products from selected individuals were cloned in pGEM T-Easy and six clones from each individual were sequenced with primers T7 and SP6.

\section{Intron Polymorphism in Populations}

A preliminary study of the population polymorphisms of the introns amplified with the developed primers was carried out in two Manila and two carpet-shell clam populations. Samples of Manila clam were taken from the Aichi prefecture (Japan), in their native range, and sent to our laboratory as 
TABLE 1.

Clam species-specific EPIC primers designed for Ruditapes philippinarum and R. decussatus.

\begin{tabular}{|c|c|c|c|}
\hline Locus & Species & Forward Primer & Reverse Primer \\
\hline \multicolumn{4}{|l|}{ TBP } \\
\hline & R. decussatus & TBP-Td-2F 5'-tgtgtacaggtgctaaaagg-3' & TBP-Td-2R 5'-ttcaaataaggtgatctatcca-3' \\
\hline & R. philippinarum & TBP-Tp-2F 5'-atccgggaaccaagaactac- $3^{\prime}$ & TBP-Tp-2R 5'-attttcttgcagccagctt-3' \\
\hline \multicolumn{4}{|c|}{ 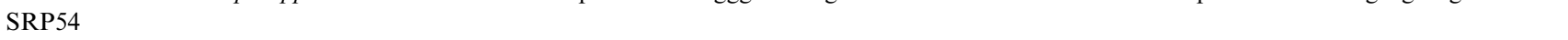 } \\
\hline & R. decussatus & SRP54-Td-3F 5'-ttaatgaagaaaatcaaacaagg-3' & SRP54-Td-3R 5' -tgtctcgcagtgtgaagtgt-3' \\
\hline & R. philippinarum & SRP54-Tp-2F 5' -tgatgaagaaaatcaaacaagg-3' & SRP54-Tp-3R 5' -tccctcaatgtgaaatgacc-3' \\
\hline \multicolumn{4}{|c|}{ 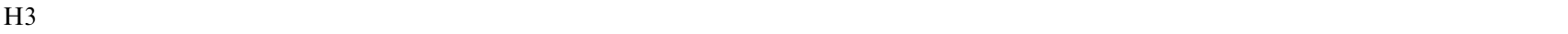 } \\
\hline & R.philippinarum & H3iA-Tp-F 5' -taacccgetagttttgagca-3' & H3iA-Tp-R 5' -cttggtggccaactgtttac-3' \\
\hline
\end{tabular}

ethanol-preserved tissue. A second sample, composed of clams from the Italian region of Veneto was studied. These clams were brought alive in the laboratory, then dissected and tissues stored frozen $\left(-80^{\circ} \mathrm{C}\right)$ until further processing. In the case of $R$. decussatus, we examined samples from an Atlantic population (Mugardos, NW Spain) and from a Mediterranean population (Venice, Italy). Animals from the Atlantic were brought alive in the laboratory, and those from the Mediterranean were sent to us as tissue preserved in ethanol.

Individual genotype data were stored in an open access database, and translated into adequate format for genetic population analysis software. Genotype and gene frequencies were calculated. Deviations from Hardy-Weinberg equilibrium (HWE) were tested by means of an exact test (Rousset \& Raymond 1995). The magnitude of the deviations from HWE was estimated with the statistics $F_{I S}$ according to Weir and Cockerham (1984). Genetic differentiation among populations was tested by an exact test (Raymond \& Rousset 1995a), and its magnitude was estimated with the statistics $F_{S T}$ as in Weir and Cockerham (1984). The computer program Genepop (Raymond \& Rousset 1995b) was used to perform all these calculations.

\section{RESULTS AND DISCUSSION}

\section{Intron Markers and Polymorphism}

We tested 3 primer pairs (arginine kinase, elongation factor $1 \alpha$, proto-oncogen int) from those designed by Palumbi and Baker (1994) and the 7 primer pairs developed by Jarman et al. (2002). Only the primer pairs for the introns of the genes coding for the TATA box binding protein / transcription factor IID (TBP) and for the signal recognition particle 54-kDa subunit (SRP54), designed by Jarman et al. (2002), produced relatively clear one or two-banded PCR products. Bands from 1-3 individuals per species and locus were cloned and sequenced. Speciesspecific primers designed from these sequences (Table 1) produced clear one and two-banded phenotypes in agarose gels, indicating the existence of ILPs in the two genes in the case of the Manila clam (Fig. 1 A and B), and in TBP, but not in SRP54, in the case of the grooved carpet-shell clam (Fig. 2 A). The analysis of the sequences of the amplified fragments confirmed the existence of insertion-deletion events (indels) causing the ILPs. After alignment of all allele sequences the most relevant variations that characterized the TBP locus of the Manila clam were indels at positions 326 (382 bp and $111 \mathrm{bp}$ long), 518 (81 bp), 655
(22 bp), 683 (24 bp), and 687(20 bp). In the case of SRP54, among-allele variation was caused by indels at alignment positions 61 (180 bp), 149 (263 bp), 454 (65 bp), and 523 (169 bp). Finally, indels at positions $280(10 \mathrm{bp})$ and $274(22 \mathrm{bp})$ differentiated the three alleles at TBP in the grooved carpetshell clam. Basic analysis of indels with Repeatmasker (Smit et al. 1996-2004) revealed no especial repeat structure. Only in the case of SRP54 the presence of a $68 \mathrm{bp}$ fragment homologous to leucine transfer RNA (tRNA-Leu-TTA) was detected when
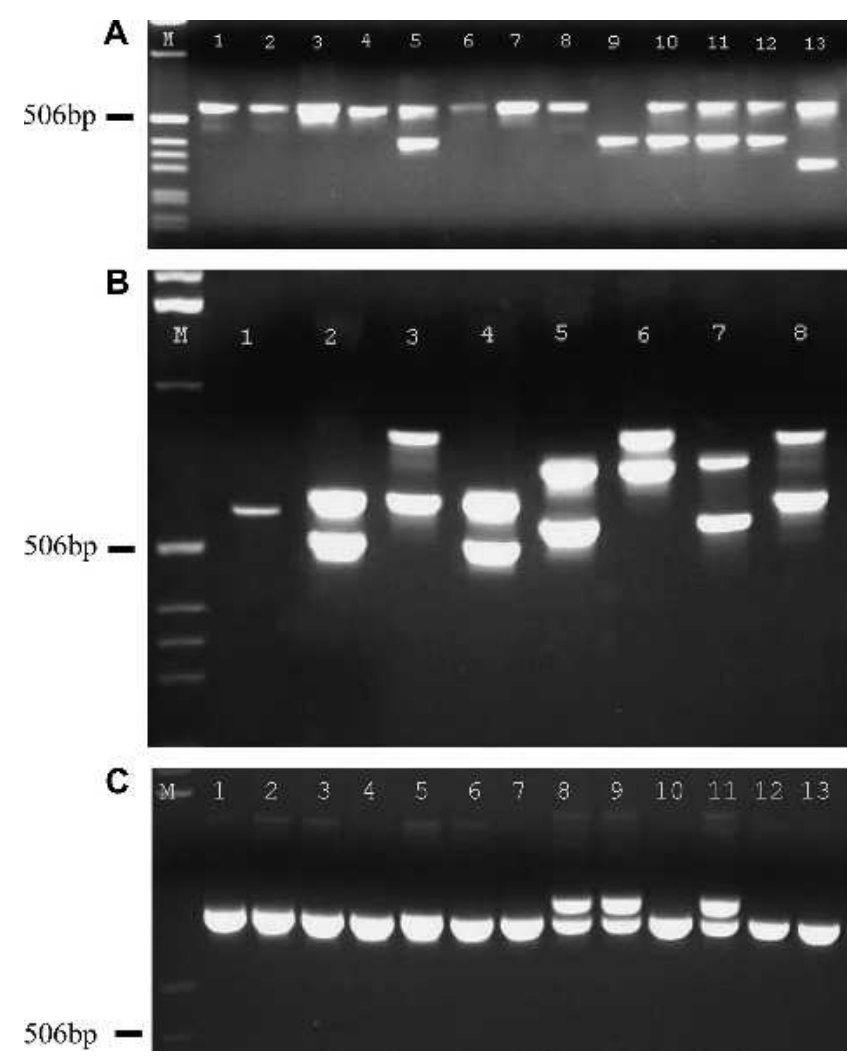

Figure 1. Examples of agarose gels showing ILP polymorphisms detected at the three loci scored in $R$. philippinarum. (A) SRP54 intron: lanes 1, 2, $3,4,6,7$, and 8; genotype 578/578; lanes 5,10,11, and 12; genotype 578/ 402; lane 9, genotype 402/402; lane 13, genotype 578/308. (B) TBP intron: lane 1, genotype 648/648; lanes 2 and 4 , genotype 648/542; lanes 3 and 8 , genotype 648/853; lanes 5 and 7 , genotype $731 / 583$; lane 6 , genotype 731/853. (C) H3-iA intron: lanes 1, 2, 3, 4, 5, 6, 7, 10, 12, and 13, genotype $755 / 755$; lanes 8,9 , and 11 , genotype $856 / 755$. 


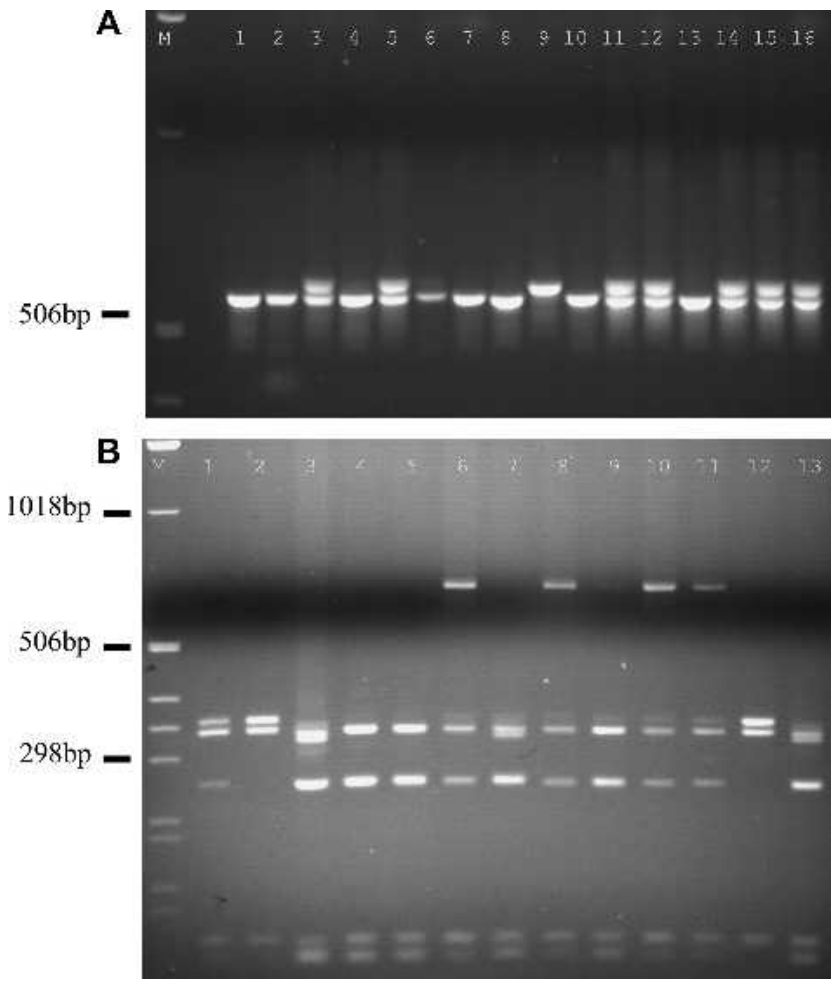

Figure 2. Examples of agarose gels showing variation at two loci in R. decussatus. (A) ILP at the TBP locus: lanes 1, 2, 4, 6, 7, 8, 10, and 13, genotype $573 / 573$; lanes $3,5,11,12,14,15$, and 16 , genotype 597/573; lane 9, genotype 597/597. (B) RFLP at SRP54 cut with EcoR I: lane 1, genotype $A / B$; lanes 2 and 12 , genotype $A / A$; lanes 3,7 , and 13 , genotype $B / D$; lanes 4, 5, and 9, genotype BB; lanes $6,8,10$, and 11, genotype $B / C$.

using human and mouse data bases for masking. This fragment was located at position 607 of the alignment.

Database mining provided 5 cDNA sequences that were long enough for intron search but only two showed the potential presence of introns after alignment with orthologous genes in model organisms. They were a $R$. philippinarum cDNA homologous to the histone 3.3A gene of mouse (GenBank accession AY916801), and another corresponding to a $\mathrm{Cu} / \mathrm{Zn}$ superoxide dismutase (SOD) (AY377969) from R. decussatus. Specific primers for 4 predicted introns were designed, but only those specific for histone 3 intron A (H3-iA) produced clear one or two-banded phenotypes, and only in the Manila clam (Fig. 1 C).

One copy of each allele from each locus and species was sequenced (GenBank accessions AM410712 to AM410723), and used to check for correct gene identity by comparing the exonic ends with orthologous GenBank accessions.

\section{Population Variability in the Manila Clam}

This species showed a multiallelic ILP at both SRP54 and TBP, and a two-allele ILP in H3-iA. Polymorphisms were observed in the two populations studied, and the common alleles were the same in Japan and Italy. Intron length variants were at similar frequencies in the two populations (Table 2), resulting in significant $F_{S T}$ only at the locus SRP54 $\left(F_{S T}=\right.$ $0.053, P=0.005$ by the exact test). Deviations from HWE were
TABLE 2.

Frequencies of length variants, heterozygosity $(h)$, and deviations from Hardy-Weinberg equilibrium $\left(F_{I S}\right)$ at three introns in 2 populations of the Manila clam, $R$. philippinarum.

\begin{tabular}{|c|c|c|c|}
\hline Locus & Allele & Japan & Italy \\
\hline \multicolumn{4}{|l|}{ TBP } \\
\hline & 583 & 0.280 & 0.259 \\
\hline & 648 & 0.200 & 0.328 \\
\hline & 542 & 0.140 & 0.172 \\
\hline & 731 & 0.240 & 0.103 \\
\hline & 853 & 0.140 & 0.138 \\
\hline & $\mathrm{N}$ & 25 & 27 \\
\hline & $h$ & 0.785 & 0.766 \\
\hline & $F_{i s}$ & 0.001 & 0.117 \\
\hline \multicolumn{4}{|l|}{ SRP54 } \\
\hline & 578 & 0.926 & 0.814 \\
\hline & 402 & 0.019 & 0.171 \\
\hline & 308 & 0.037 & 0.014 \\
\hline & 799 & 0.019 & 0.000 \\
\hline & $\mathrm{N}$ & 27 & 35 \\
\hline & $h$ & 0.140 & 0.308 \\
\hline & $F_{i s}$ & -0.035 & 0.362 \\
\hline \multicolumn{4}{|l|}{ H3-iA } \\
\hline & 856 & 0.109 & 0.194 \\
\hline & 755 & 0.891 & 0.806 \\
\hline & $\mathrm{N}$ & 32 & 31 \\
\hline & $h$ & 0.194 & 0.313 \\
\hline & $F_{i s}$ & -0.107 & -0.224 \\
\hline
\end{tabular}

nonsignificant in all cases (Table 2). The similarity of the two Manila clam populations both in heterozygosity and allelic frequencies is remarkable in spite of the distance between them. However, we should consider that the Italian population was founded with a subsample of the Asian populations (Flassch \& Leborgne, 1992). A second potential consequence of the introduction of Asian Manila clam in Europe could be loss of genetic variability caused by a founder effect. AlI alleles detected in the Japanese sample were present in the Italian sample, with the exception of allele 799 at SRP54. This allele was at low frequency $(1.8 \%)$ in the Japanese sample. Therefore, it could have been missed in the Italian sample caused by sampling error. Heterozygosity at two loci (SRP54 and H3-iA), out of three scored, is lower in the Japanese population than in the Italian, suggesting the signature of genetic drift or selection on these loci, but not extreme founder effects. In summary, the data suggest that no variability losses have taken place during the introduction of the Manila clam in the Italian region of Veneto, and that the founding population carried most of the genetic variability existing in the original Pacific populations. However, more markers and populations have to be scored to be conclusive.

\section{Population Variability in the Grooved Carpet-Shell Clam}

Frequencies of the intron size variants at the locus TBP in the carpet shell clam populations are given in Table 3. Deviations from HWE were not significant. Whereas the commonest alleles were the same in the 2 populations, allele frequencies clearly varied, resulting in a highly significant $F_{S T}$ value of 0.339 $(P<0.001)$. 
TABLE 3.

Frequencies of length variants, heterozygosity $(h)$ and deviations from Hardy-Weinberg equilibrium $\left(F_{I S}\right)$ at the TBP intron locus, in 2 European populations of the grooved carpet-shell clam, Ruditapes decussatus. $\mathbf{N}$ is the number of individuals scored in each population.

\begin{tabular}{lccc}
\hline \hline & & \multicolumn{2}{c}{ Populations } \\
\cline { 3 - 4 } Locus & Allele & Mugardos & Venice \\
\hline TBP & & & \\
& 597 & 0.227 & 0.647 \\
& 573 & 0.773 & 0.250 \\
& 583 & 0.000 & 0.103 \\
& $\mathrm{~N}$ & 33 & 34 \\
& $H$ & 0.351 & 0.508 \\
& $F_{\text {is }}$ & -0.106 & -0.143 \\
SRP54 & & 0.233 & 0.257 \\
& $\mathrm{~A}$ & 0.517 & 0.657 \\
& $\mathrm{~B}$ & 0.150 & 0.000 \\
& $\mathrm{C}$ & 0.100 & 0.086 \\
& $\mathrm{D}$ & 30 & 35 \\
$\mathrm{~N}$ & 0.646 & 0.495 \\
& $H$ & -0.067 & 0.090 \\
& $F_{\text {is }}$ & &
\end{tabular}

In the case of SRP54, where no intron length polymorphism was found in R.decussatus, we studied RFLP polymorphisms with the restriction enzyme EcoR I. We found a total of 4 different haplotypes (Fig. 2 B), whose population frequencies are given in Table 3 . Restriction site changes responsible for the observed RFLP variability were confirmed by sequencing selected individuals. The most common haplotype was the same in all populations (B). The frequencies varied significantly across populations $(P<0.001)$, resulting in $F_{S T}=0.021$. Tests for HWE were nonsignificant (Table 3 ).

The contrasting amounts of differentiation between the two loci in the two populations of the grooved carpet-shell clam is striking, and several explanations can be considered. The life history of clams includes a planktonic larval phase of at least 2 wk, which would preclude genetic differentiation caused by restrictions to gene flow. On the other hand, genetic differences between the Atlantic and the Mediterranean populations have been reported in the literature for a number of marine species, including several bivalves (Quesada et al. 1995a; Quesada et al. 1995b, Ríos et al. 2002, Saavedra \& Peña 2005). These differences have been explained by fragmentation and divergence during glacial periods (Quesada et al. 1995b, Bargelloni et al. 2003). Finally, stabilizing selection at SRP54 or diversifying selection at TBP could be responsible of the contrasting patterns observed at the two loci. The study of more populations is necessary to characterize the pattern of variability in the grooved carpet-shell clam and check if it corresponds to widespread restriction to gene flow or to an Atlantic/Mediterranean differentiation pattern. It is also necessary to increase the number of intronic markers studied and to compare them with other types of markers, to give accurate explanations for the genetic differentiation observed.

\section{ACKNOWLEDGMENTS}

The authors thank Paolo Bremer (CNR, Italy), K. Kobayashi (FAIAQUA Co. Ltd., Japan), and Dorotea Martínez (CIMAXunta de Galicia, Spain) for providing clam samples. This work has been funded by research grants AGL2003-04143 and AGL2006-08944 to J.B.P., and by the "Ramón y Cajal" program (C.S.), from the Spanish Ministry of Education and Science.

\section{LITERATURE CITED}

Bargelloni, L., J. A. Alarcon, M. C. Alvarez, E. Penzo, A. Magoulas, C. Reis \& T. Patarnello. 2003. Discord in the family Sparidae (Teleostei): divergent phylogeographical patterns across the AtlanticMediterranean divide. J. Evol. Biol. 16:1149-1158.

Borsa, P., P. Jarne, K. Belkhir \& F. Bonhomme. 1994. Genetic structure of the palourde Ruditapes decussatus L. in the Mediterranean. In: A. R. Beaumont, editor. Genetics and evolution of aquatic organisms. London: Chapman \& Hall. pp. 103-113.

Corte-Real, H. B .S. M., D. R. Dixon \& P. W. H. Holand. 1994. Intron targeted PCR: a new approach to survey neutral DNA polymorphism in bivalve populations. Mar. Biol. 120:407413.

Flassch, J. P. \& Y. Leborgne. 1992. Introduction in Europe, from 1972 to 1980, of the Japanese Manila clam (Tapes philippinarum) and effects on aquaculture production and natural settlement. ICES Mar. Sci. Symp. 194:92-96.

Hall, T. A. 1999. BioEdit: a user-friendly biological sequence alignment editor and analysis program for Windows 95/98/NT. Nucleic Acids Symp. Ser. 41:95-98.

Hassan, M., C. Lemaire, C. Fauvelot \& F. Bonhomme. 2002. Seventeen new exon-primed intron-crossing polymerase chain reaction amplifiable introns in fish. Mol. Ecol. Notes 2:334-340.

Helm, M. \& M. Pellizzato. 1990. Hatchery rearing and breeding of the Tapes philippinarum species. In: Tapes Philippinarum. Biologia e esperimentazione. E.S.A.V., Trieste (Italy).
Hurtado, S., P. Morán \& J. J. Pasantes. 2006. Genetic evidence of natural hybridization between Ruditapes decussatus and $R$. philippinarum. International Congress on Bivalvia, Bellaterra (Spain).

Jarman, S. N., R. D. Ward \& N. G. Elliott. 2002. Oligonucleotide primers for PCR amplification of coelomate introns. Mar. Biotechnol. 4:347-355.

Jensen, A. C., J. Humphreys, R. W. G. Caldow, C. Grisley \& P. E. J. Dyrynda. 2004. Naturalization of the Manila clam (Tapes philippinarum), an alien species, and establishment of a clam fishery within Poole Harbour. Dorset. J. Mar. Biol. Ass. UK. 84:10691073.

Jones, G. G., C. L. Stanford \& B. L. Jones. 1993. Manila clams: hatchery and nursery methods. Vancouver: B.C. Sience Council.

Lessa, E. P. 1992. Rapid surveying of DNA sequence variation in natural populations. Mol. Biol. Evol. 9:323-330.

McGinnis, S. \& T. L. Madden. 2004. BLAST: at the core of a powerful and diverse set of sequence analysis tools. Nucleic Acids Res. 32:W20-W25.

Ohresser, M., P. Borsa \& C. Delsert. 1997. Intron length polymorphism at the actin gene locus mac-1: a genetic marker for population studies in the marine mussels Mytilus galloprovincialis Lmk and M. edulis L. Mol. Mar. Biol. Biotechnol. 6:123-130.

Paesanti, F. \& M. Pellizzato. 2000. Tapes philippinarum: manuale sulla vongola verace d'allevamento. Veneto Agricoltura, Legnaro. 
Palumbi, S. R. 1996. Nucleic acids II: the polymerase chain reaction. In: D. M. Hillis, C. Moritz \& B. K. Mable, editors. Molecular systematics, 2nd ed. Sinauer, Sunderland. pp. 205-247.

Palumbi, S. R. \& C. S. Baker. 1994. Contrasting population structure from nuclear and mtDNA of humpback whales. Mol. Biol. Evol. 11:426-435.

Pranovi, F., G. Franceschini, M. Casale, M. Zuchetta, P. Torricelli \& O. Iovanvardi. 2006. An ecological imbalance induced by a non-native species: the Manila clam in the Venice lagoon. Biol. Invasions 8: 595-609.

Quesada, H., C. Zapata \& G. Alvarez. 1995a. A multilocus allozyme discontinuity in the mussel Mytilus galloprovincialis: the interaction of ecological and life-history factors. Mar. Ecol. Prog. Ser. 116:99-115.

Quesada, H., C. M. Beynon \& D. O. F. Skibinski. 1995b. A mitochondrial DNA discontinuity in the mussel Mytilus galloprovincialis Lmk: Pleistocene vicariance biogeography and secondary intergradation. Mol. Biol. Evol. 12:521-524.

Raymond, M. \& F. Rousset. 1995a. An exact test for population differentiation. Evolution Int. J. Org. Evolution 49:1280-1283.

Raymond, M. \& F. Rousset. 1995b. GENEPOP (version 1.2): population genetics software for exact tests and ecumenicism. J. Hered. 86:248-249.

Ríos, C., S. Sanz, C. Saavedra \& J. B. Peña. 2002. Allozyme variation in populations of scallops, Pecten jacobaeus (L.) and P. maximus (L.), across the Almeria-Oran front. J. Exp. Mar. Biol. Ecol. 267:223-244.

Rousset, F. \& M. Raymond. 1995. Testing heterozygote excess and defficiency. Genetics 140:1413-1419.

Rozen, S. \& H. Skaletsky. (2000). Primer3 on the WWW for general users and for biologist programmers. In: S. Krawetz \& S. Misener, editors. Bioinformatics methods and protocols: methods in molecular biology. Totowa, New Jersey: Humana Press. pp. 365-386.

Saavedra, C. \& J. B. Peña. 2005. Nucleotide diversity and Pleistocene population expansion in Atlantic and Mediterranean scallops (Pecten maximus and P. jacobaeus) as revealed by the mitochondrial 16S ribosomal RNA gene. J. Exp. Mar. Biol. Ecol. 323:138150 .

Sambrook, J. \& D. W. Russell. (2001). Molecular cloning: a laboratory manual, 3rd ed. Cold Spring Harbor, New York: Cold Spring Harbor Laboratory Press.

Smit, A. F. A., R. Hubley \& P. Green. RepeatMasker Open-3.0. 1996 to $2004<$ http://www.repeatmasker.org $>$.

Thompson, J. D., D. G. Higgins \& T. J. Gibson. 1994. CLUSTAL W: improving the sensitivity of progressive multiple sequence alignment through sequence weighting, positions-specific gap penalties and weight matrix choice. Nucleic Acids Res. 22:4673-4680.

Touriya, A., M. Rami, G. Cattaeno-Berrebi, C. Ibañez, S. Augros, E. Boissin, A. Dakkak \& P. Berrebi. 2003. Primers for EPIC amplification of intron sequences for fish and other vertebrate populatio genetic studies. Biotechniques 35:676-682.

Villablanca, F. X., G. K. Roderick \& S. R. Palumbi. 1998. Invasion genetics of the Mediterranean fruit fly: variation in multiple nuclear introns. Mol. Ecol. 7:547-560.

Weir, B. S. \& C. C. Cockerham. 1984. Estimating F-statistics for the analysis of population structure. Evolution Int. J. Org. Evolution 38:1358-1370.

Yasuda, N., S. Nagai, S. Yamaguchi, C. L. Lian \& M. Hamaguchi. 2007. Development of microsatellite markers for the Manila clam Ruditapes philippinarum. Mol. Ecol. Notes 7:43-45. 